affected by pressure than those with small ones; and consequently the transitions between the large orbits may be more affected than those between small ones.

The effect of temperature will be parallel to that of pressure. At low temperature the valence electron is moving only between orbits with small radius, but as the temperature becomes higher the collisions between atoms become more energetic and the valence electrons are ejected to orbits with larger radius.

It may be of interest to remark finally that the lines of Group e, having displacements to the violet side, remain as yet out of the multiplets.

The work is being extended to other elements. M. A. Catalán.

Laboratorio de Investigaciones Físicas, Madrid, May I.

\section{Sunshine and Health in Different Lands.}

Mr. W. H. Dines's letter in NATURE of May 3I is very helpful in bringing this discussion to a head. The inevitable association, in the long run, of sunshine with heat is, of course, the crux of the whole matter considered as a climatological problem, and there is much to support the contention that, on the whole, cool climates are more benign and conducive to general health and vigour than warm. This climatological problem should not be confused with the hygienic problem of securing proper access to, or making the best use of, such allowance of sunshine as each climate affords. This latter is, no doubt, the aspect of the question with which the medical faculty and the "sunlight league" are more immediately concerned, but sooner or later they will be confronted with the wider geographical or climatological relationships of the subject.

The problem of comparing different lands for the purpose of finding and evaluating a sunshine optimum turns upon the possibility of isolating sufficiently the effect of direct sunlight from the effects of the associated conditions of temperature, moisture, and windan obviously difficult matter. One might, for example, think that if there were a little more winter sunshine England would come very near, indeed, to the general climatic optimum from the point of view of general salubrity. But the trouble is that any alteration in an average of sunshine would, almost inevitably, be associated with a redistribution in the average conditions of temperature, moisture, and wind, with the risk that more sunshine in England might easily mean a less favourable total combination of climatic elements than the country actually enjoys. It becomes a question of "leaving well alone" ! Hence the practical climatological problem is narrowed down to this: What countries approach most closely to a combined optimum integrating the effects of sunlight, temperature, moisture, and wind conditions, including the stimulating influence upon mind and body of frequent, yet not too violent, changes of weather, and storms? There can be no doubt that in respect to this totalisation of effects, in which sunshine is included, Britain stands very high; but no comparison between this and other European, or extra-European, countries would be trustworthy without rigorous investigation. Mortality and longevity statistics may furnish an index of what is required, but they need to be very cautiously interpreted, inasmuch as the onset of disease and senility is largely controlled by various conditions for which climate cannot fairly be held responsible.

27 Tanza Road

Hampstead, N.W.3, June $I$.

L. C. W. BONACINA.

NO. 285 I, VOL. I I 3$]$

\section{The Modus Operandi of Kidney Secretion.}

Prof. Swale Vincent, in his recently issued " Introduction to the Study of Secretion," refers, in the chapter on kidney secretion, to my proof (Journ. and Proc. Asiatic Soc., Bengal, N.S., vol. xviii. pp. 85I93, I922) that the network of renal afferent veins in the substance of the frog's kidney has nothing to do with renal secretion, and states that this discounts most or all of the evidence (Bainbridge and Beddard and others) hitherto advanced in support of the idea that the tubules secrete. I submit that this does not represent the position. I have shown in the paper above quoted that it is almost certain that the secretion obtained by Bainbridge and Beddard in the frog's kidney, when the arteries were ligatured, was due solely to venous blood percolating into the true capillaries surrounding the tubules, and this necessarily implies secretion by the tubules.

May I suggest that the respective rôles of the tubules and glomeruli in the kidney can be established once for all if, in a living mammal, with blood charged with diuretic, the circulation in one kidney be reversed, the other kidney being maintained normal as a control ? This can be effected by rapidly joining up the half of the renal artery next the aorta (or a mesenteric artery, if more convenient, the flow through which can be compared with that through the normal control renal artery afterwards) with the renal vein, the renal artery (the half next the kidney) being simultaneously connected with a vein. This operation, in these days of expert surgery, should not prove to be an impossible one (and I speak from experience gained in preliminary attempts to perform the experiment in India), the connexions between the arteries and veins being effected either by means of Hédon tubes or glass tubes internally coated with paraffin-vaseline mixture, as suggested by Bazett and Quinby (Quart. Journ. Exp. Physiol., vol. xii., r920), and the theoretical importance of it is manifest if, as I anticipate from the results of my own similar saline perfusion experiments, the secretion from the kidney with reversed blood flow will prove to be five to eight times as great as that from the normal control kidney, despite perturbations due to the temporary interruption of its blood flow.

Wellcome Bureau of Scientific Research, W. N. F. WoOdLand. 25-27 Endsleigh Gardens, London, N.W.I.

\section{Emission of Volcanic Gases.}

AT Solfatara, south of Naples, in the crater of what is called locally the "little Vesuvius" many of the delegates who visited Naples for the recent University celebrations saw the following puzzling phenomenon. Gas (or vapour) issues from various holes in the floor of the crater and in the walls. The guide ignites a resin torch which he waves over one of the holes. Immediately the volume of gas issuing from the hole becomes denser, and not only that, but the other holes apparently instantaneously become more active, giving out more gas, even though some of these holes are hundreds of yards away. Although the observations were necessarily of a very rough kind, yet every one who saw it agreed as to what was observed. I heard no one who could give any explanation, and my idea that the phenomenon was largely subjective found no supporters. A. W. Conway.

University College, Dublin, May I5, 1924. 